\title{
DIGITAL LEARNING PLATFORM SERVICES
}

\author{
Aleksandrova L. A. ${ }^{1}$, associate professor, ludmilasis@mail.ru \\ Galimov E. R. ${ }^{1}$, postgraduate student, 96bedward@mail.ru \\ ${ }^{1}$ Kazan National Research Technical University named after A.N.Tupolev, \\ 10, Karl Marks st., 420111, Kazan, Russia
}

\begin{abstract}
This paper analyzes digital technologies in the modern educational process, offers training and control services, formed with the help of the Learning Management System (LMS), which allows one to organize an active, creative and social training of modern specialists, in accordance with the program of "Digital economy of the Russian Federation". The paper analyzes modern learning technologies and existing services of digital platforms. The capabilities of digital platforms are demonstrated on the basis of LMS Blackboard. Training and control measures are offered which will allow forming and evaluating the specialists' competencies. The authors have developed a model "Business game" that is implemented based on the LMS Blackboard and with the help of software complex "SMARTlabwork". The results of the analysis of parameters of quality of performance of various training and control actions received by means of methods of the intellectual analysis (Data Mining) are presented. Essential signs of control measures and competence indicators are recommended.
\end{abstract}

Keywords: learning management system, train and control means, data mining, e-learning.

Citation: L. A. Aleksandrova and E. R. Galimov, "Digital Learning Platform Services", Computer tools in education, no. 1, pp. 79-87, 2019 (in Russian); doi:10.32603/2071-23402019-1-79-87

\section{INTRODUCTION}

In accordance with the program "Digital economy of the Russian Federation", the problem of creating a digital platform for training and development of young professionals, development and forecasting of their competencies is currently relevant. The transition to the digital economy requires human resources with an expanded set of competencies, such as management, communication, information [1, 2]. The expansion of professional and non-professional competences of specialists necessitates the introduction of new forms and technologies of training, improvement of traditional, intellectual methods of assessment, acquired competencies [2-6].

The solution of these tasks requires the creation of a digital learning platform. The development of digital science is one of the most modern paradigms [1, 7]. The model of such a platform can be implemented on the basis of Learning Management System. The developed platform should take into account the interests of various stakeholders, such as science, engineering, business, management [3, 8]. 
This paper analyzes the existing set of LMS services and their capabilities (for example, Blackboard LMS), offers new tools for social learning, development of scientific creativity, evaluation and improvement of staff:

- "Business game" models and technologies,

- Models of SMART technologies $[9,10]$ for laboratory work,

- Software package "SMARTlabwork" [9] which allows you to train, monitor the learning process and evaluate the acquired competencies.

Data mining methods carried out an analysis of training and control activities, procedures for assessing competencies, identified significant features and parameters that will allow, in the future, to automate and create MOOC (Massive Open Online Courses) and SMART courses.

\section{MODERN TRENDS AND CONCEPTS IN CONTEMPORARY EDUCATION}

Education is a process that should be constantly improved and modernized. Contemporary education is impossible without digital educational tools that expand, enrich, and provide such new opportunities as organizing and managing forums, conferences, and webinars. Speaking about digital educational tools, we mean the use of the (LMS) Learning Management System, a system for creating digital learning platform and managing the learning process. Digital learning platform is an environment with broad opportunities implementing the e-learning, SMART, CDIO and other modern technologies and learning concepts.

E-learning is a very broad concept covering such ideas in the learning process as "electronic learning" (e-learning), "enterprise" (entrepreneurship in the learning process implying the use of innovative technologies), "everywhere" (learning everywhere and for everybody), "every time" (any time), "excellent" (excellent, or top quality education - adapting learning / learning meeting the learner needs), "experience" (learning from experience, and using experiences of other universities, enterprises, and training centers).

SMART is used in management and project management for setting goals and developing (Specific Measurable Attainable Relevant Time-bounded) tasks. The quality of the learning process, as a rule, depends on a management strategy; therefore SMART technologies are applied to the learning process. Mention should be made that in Russian-language publications the "SMART" abbreviation is translated as "smart" and used in such expressions as "smart things", "smart technologies", and "smart education".

Endowing inanimate objects with intelligence is a rewarding and promising task (there have appeared smart kettles, smart vacuum cleaners, etc.). Smart education is an ambiguous concept and, in fact, it is based on e-learning technologies. In Russian issues [4] SMART technologies in education are calling for allying educational institutions and faculties to make joint educational efforts on the Internet based on general standards, agreements and technologies. The project of the next decade proposed in the European education system is the Common European University. Naturally, SMART education is based on the digital technologies.

CDIO (Conceive Design Implement Operate), the official community of universities offering practice-oriented education, has developed a set of general principles to develop curricula and logistics, select and train teachers. The CDIO is a modern approach to engineering education in the context of conceiving, designing, implementing and operating real-world systems and products.

Digital technologies play an important role in making electronic content for the learning process as well. On one hand, abundant open educational resources and MOOC facilitate the educator's work [4, 5], and, on the other hand, they make the educator feel responsible for authenticity, relevance, and significance of the instructional content used. 


\section{THE ROLE AND OPPORTUNITIES OF THE LMS IN CONTEMPORARY EDUCATION}

To implement modern educational concepts, first of all, it is necessary to create a digital educational environment (DEE), based on the promising and certified LMS. Unfortunately, a great number of educational institutions are developing a DEE on their own, which is unjustified, as it affects the time of implementation and the quality of the DEE. Another significant drawback of self-designed DEEs is the incomplete use of e-learning opportunities.

We will demonstrate the capabilities of the DEE at Kazan National Research Technical University - Kazan Aviation Institute (KNRTU-KAI), working on the basis of the Blackboard LMS, and present the most effective learning methods and monitoring techniques that allow implementing the principles and requirements of such modern e-learning and monitoring concepts as activity, creativity, communicativeness, flexibility, individuality, motivation, feedback, transparency and many parametrizations in the assessment and monitoring procedures.

We believe that the most effective and promising tools and instruments of the LMS are "Blogs", "Discussion board", "Wikis", "Self-assessment and Evaluation of Partner", "Blackboard Collaborate", tools for creating a variety of testing formats, instruments for controlling testing procedures and evaluating test results ("Tests, Surveys and Pools" module), enabling assessment reports to reflect various characteristic features of the learning process: basic and supplementary teaching materials used, amounts of time spent, individual or group work assessment ("Reports on the course" module). We will demonstrate how using the proposed tools and instruments may help implement different learning methods and monitoring techniques, and we will demonstrate their capabilities, and junior and senior students' attitudes to them.

At the present time, the focus has to be dynamically shifted from educating to learning. Educating is acquiring information programmed or given by the educator or determined by the educating standards. The learners being active is becoming an important component of the learning process.

The learner is supposed to be active when searching, acquiring, and processing information, doing a variety of assignments and tasks, both during the learning process and monitoring or testing procedures. Any monitoring and learning activities suggest the learner's being active to a greater or lesser extent, however, the learner may be actively engaged in forums, conferences, and webinars. Learners' engagement in these activities is increased by discussing interesting, relevant, topical and acute issues and the educator's ability to guide discussions and keep the learners "interested" throughout the whole session. According to the analysis findings the firstyear students are most engaged in forums (on average, we got 20 entries within 5 days per 1 person) and in e-conferences (about 5 entries within 3 days). These activities develop the firstyear students' skills to formulate, express and support their ideas, and keep a discussion session going.

Being active might be visible (participation for the sake of participation), and should be for the sake of knowledge. Participating in such events should encourage the learner's creativity. Presenting the known facts is undesirable. The learner's being creative might involve searching for errors and inaccuracies, coming up with new ideas, generalizing acquired knowledge, and so on.

The environment for learners to be creative is designed using such tools as "Discussion board", "Wikis", "Self-assessment and Evaluation of Partner". The "Discussion Board" tool is traditionally used for organizing forums and conferences. The "Wiki pages" tool has a very wide application. It is the most useful tool to organize learners doing term theses, course projects, and "Business games". This tool is necessary for an educator who is supposed to actively manage 
learners' work. The "Self-Assessment and Evaluation of Partner" tool is recognized as the most promising tool to develop learners' creative skills. This tool encourages and organizes learners' creative attitude to the processes carried out by a learner and his/her partners. It is well known that the most effective approach to learning is learning from your mistakes or teaching others.

\section{BUSINESS GAME, AS THE MOST INFORMATIVE AND PROMISING LEARNING METHOD AND MONITORING TECHNIQUE}

One of the key competencies that graduates must master is social and communicative competence. The electronic educational environment using the "Business Game" method allows you to simulate such social networking mechanisms as group work, competition, self-evaluation, evaluation of partners, setting goals and developing tasks and solutions, and organizing activities. At present, the "Business Game" method is a very common and effective mechanism simulating real-business situations, social networking space, processes and systems that graduates may face in their professional life in the future..

Business games in our courses use Blackboard platform tools such as Blogs, Discussion board, Wikis, Self-assessment and evaluation of partner, Collaborate.

The concept of "business game" is a generalized concept. Other variants of the name are a role-playing game, a method of projects and a "war game". We describe the scenario of a "business game" that is used in the discipline "Security of confidential documents".

- Creation of a mini-group for the implementation of the project "Secured workflow of organization".

- Select an organization profile.

- Justification of their competencies by members of the group.

- Selection of the team leader and justification of his competencies.

- Description of the organization's infrastructure.

- Discussion of activities to solve the problem by all members of the group.

- Joint development of an action plan for creating a project. Appointment of terms and performers, that is, all members are receiving individual tasks.

- Team members offer solutions to their individual tasks. Decisions are first adjusted by the teacher using the Wiki, and then evaluated by the partners of the group using the means of "Self-assessment and evaluation of the partner".

All events and decisions are discussed by group members and commented on by the leader (teacher) using the forum and the Wiki tool.

This learning method and monitoring technique at the same time, allows learners to learn how to collaborate, carry out constructive discussions, support their ideas and points of view, and respond to criticism and comments. Working in a group, according to the proposed scenario, improves learners' cooperation skills and oral and written communication culture in general.

Designing military-themed computer and video games gave birth to the term "Business game". Currently, this term is used alongside with the term "War game", as competitive intelligence may be the basis for almost any field. "War games" always involve confrontation, competition and should be built on analyzing real-life situations and forecasting possible actions. This game is neither war nor game [11]. This training is in the form of a game to analyze, search for the necessary information and perform the necessary actions. Such games are very effective, especially for studying various models of information security.

But this game cannot be implemented using available tools of the DEE only. Therefore, a software package was developed for performing laboratory work in order to study the "peer to peer 
authentication" and "generalized digital signature" models, which are studied in various disciplines of the "Information Security" direction [9]. The software package models two scenarios: working in a friendly environment and working in an unfriendly environment (the last scenario involves intruders' actions). The learner is supposed to recognize the scenario and work in accordance with the protocols. During the execution of tasks student's actions are controlled and his theoretical knowledge is evaluated. The software package registers the number of attempts made to perform various scenarios of the laboratory work, the errors in friendly and unfriendly scenarios made, the quality of completed reports, the test assignments where errors were found, the number of testing attempts, and total time spent doing the lab work.

On the basis of this data, the student's level of competence is determined by the methods of artificial intelligence. The software package developed takes into account the principles of CDIO and SMART technologies, so we could call it SMART laboratory work (SMARTlabwork).

\section{KNOWLEDGE AND COMPETENCIES ASSESSING TECHNIQUES USING DATA MINING}

Technology assessment of knowledge and competencies are determined by control measures, indicators of quality for the implementation of measures, assessment methods.

\section{A. Technologies and services of control measures}

All of the learning methods described serve as monitoring and evaluating. Monitoring is necessary to manage the learning process and always includes assessing process. All the LMS Blackboard tools that may be used for learning and evaluating their accomplished tasks use the "Evaluation criterion" service. When working with this service, you must specify the quality indicators of the task, their weight and the levels of achievement of each indicator. For example, quality indicators can be indicators such as deadlines, autonomy, initiative, innovative and creative approach, etc. The levels of achievement can be estimated with 3-5 gradations, such as high, low, medium, below average, above average. The "Evaluation criterion" service is extremely useful.

The main advantage of this service is transparent evaluating of the tasks accomplished. On the other hand, work with this service is complicated:

- Selection of informative indicators of quality and their weight,

- Definition levels of achievement of each indicator,

- The complexity of the assessment process.

The difficulty lies in the fact that the desire to improve the accuracy of the assessment of the event leads to an increase in the number of indicators and, consequently, an increase in the complexity of the assessment the course.

To automate the process of assessing knowledge and competencies you may use the "Reports on the Course" and "Elements Analysis" tools.

The "Reports on the course" tool contains a large number of reports that can be used to form a set of indicators to evaluate a learning process. You can automate the process of assessing knowledge and competencies using indicators such as how long a student spends on a DEE course, how long he spends on various tasks, what elements of the course he works with (basic material, additional material, forums, blogs, wikis, etc.).

The "Elements Analysis" tool characterizes the testing process, determines the complexity of test tasks, and allows students to be identified using Data Mining methods based on the number of correct answers to test tasks of varying complexity, shape, and topic. 


\section{B. Selecting significant indicators for monitoring and assessment}

To deal with this problem we used the "Statistica" and the "Deductor" software, and the Data Mining methods.

This problem was solved according to the following scenario:

- Defining a set of quality indicators and the levels of achievement for each indicator. Making the primary sample. Clustering (determining an optimal number of clusters).

- Verifying interpretation of the formed clusters.

- Making a learning sample based on the constructed clusters if interpretation is possible.

- Making a learning sample by an expert if interpretation is impossible.

- The method of neural networks to solve the task of recognition (learning with the teacher).

- If the method gives a qualitative solution, then using the "Solution Tree" method, determine significant indicators of quality and levels of achievements.

- If the method does not provide a qualitative solution, then either there are no significant indicators, or the expert uses erroneous recognition images and further research stops.

According to the proposed scenario, we have completed three tasks. Data for completing these tasks were obtained during the learning process with the DEE at KNRTU-KAI.

The first task was to determine significant indicators for such a monitoring procedure as testing. This task was solved on the basis of data obtained using the tool "Elements Analysis". For this task, the following indicators were chosen: the percentage of correct answers to test tasks of varying complexity, shape, and topic. Clusters were built using the methods of hierarchical cluster analysis. The best clustering ( 4 clusters) was determined by the k-means method. The constructed clustering was interpreted by an expert as trainees with a high level of training, a low level of training, and two clusters of trainees with an average level of training. The last two clusters did not have a clear interpretation. The "Solution Tree" method showed the significance of the indicators associated with complex forms of test tasks. The percentage of correct answers to the test task with one correct answer is the most insignificant indicator.

The second task was to determine significant indicators when using the "Evaluation Criteria" service. In this case, the educator has a set of parameters worked out in the working process [10]: following due time for doing tasks, making accurate reporting documents, being independent and active, studying educational content deeply and thoroughly, being a creative and a persuasive speaker etc.

An expert (teacher) evaluates each indicator with the help of five or three levels of achievement. Completing this task, the expert (educator) interprets the constructed clusters easily. All indicator of this task, may be considered informative, but the most significant indicator is recognized, curiously enough, the "time of doing task" parameter, the "learner's independence" parameter is highly informative as well. The "learner's being active" parameter yields little information.

The third task was to define significant indicators for evaluating a task on the basis of data obtained from reporting forms. From reporting forms, you may generate a significant number of indicators of the completed task. This task involves more automation to create the primary sample. Report forms contain information about the time that a learner spent working with various elements of the course, the total time spent, the number of visits to the course, and so on. A large number of indicators significantly complicate the process of clustering. As far as our case is concerned, we didn't manage to form a set of indicators for successful clustering. For the case of learning with a teacher, it was not possible to create qualitative decision rules. We believe the problem is the set of indicators. It is necessary to eliminate nonessential indicators 
and add new ones. We managed to identify one of the indicators that significantly affected the recognition, this is the number of elements of the DEE course with which the student worked. The course can contain from 30 to 50 elements.

\section{Outcome and intermediate certification of knowledge and competencies}

For the final and intermediate certification of the student, it is necessary to take into account the results of all completed control measures. For this, we form a "digital footprint" of the learner. "Digital footprint" contains indicators of the quality of performance of all control measures. Next, on the basis of the sample containing the data of the "digital footprint", it is necessary to build competence clusters, then to form decision rules and select significant indicators of competencies.

The solution to this problem is complicated by the large number of "digital footprint" parameters and the complexity of calculating their values. That is why we pay great attention to the task of determining the significant indicators of the control measures being conducted. The process of combining all information systems of the university will automate obtaining values of the necessary indicators. Thus, to solve this problem, it is necessary to digitize all the processes and do their docking.

\section{CONCLUSION}

In accordance with the "Digital Economy" program, which includes the creation of "Digital Universities" and the training of specialists for the development of the digital economy, the following tasks come to the fore:

- Creation of digital learning platforms,

- The use of existing LMS services and their expansion by creating their own software,

- Development of new forms of education for the training of specialists of the digital economy,

- Development and improvement of methods for assessing the knowledge and competencies of a specialist based on artificial intelligence methods,

- Automation of the teacher's routine work through the use of SMART technologies.

In connection with the above tasks, the authors are currently working on the task of digital transformation of existing information systems to the "Digital University".

At the same time, the work done allows us to continue solving the problem of graduate competency assessment using the student's "digital footprint", which reflects all the activities of the student and is formed by all information systems.

\section{References}

1. A. K. Gorshenin, "Development of Services of Digital Platforms to Overcome Nonfinancial Barriers,” Informatics and Applications, Vol. 12, no. 4, pp. 106-112, 2018 (in Russian); doi: $10.14357 / 19922264180415$

2. A. I. Govorov, M. M. Govorova, E. V. Slizen, J. O. Valitova, and S. E. Ivanov, "Method for Constructing an Individual Educational Route By Completing Tasks for Training Professional Skills in Compiling SQL-querie,” Computer tools in education, no. 4, pp. 45-62, 2018 (in Russian); doi:10.32603/2071-23404-45-62

3. A. V. Suvorova, K. R. Smirnova, E. A. Budin, T. V. Tulupyeva, A. L. Tulupyev, and M. V. Abramov, "Research Project as a Tool for Teaching Text Analysis Methods: Predicting the Post Class in the Social Network," Computer tools in education, no. 3, pp. 49-64, 2018 (in Russian). 
4. V. Tikhomirov, N. Dneprovskaya, and E. Yankovskaya, “Three dimensions of smart education,” Smart Innovation, Systems and Technologies, Vol. 41, pp. 47-56, 2015 (in Russian).

5. A. A. Beloglazov, L. B. Beloglazova, I. A. Beloglazova, O. L. Maltsev, E.V. Trubacheev, S. A. Nikiforova, and V.V. Popenko, "Educational Technologies of Online-Learning: Analysis of Mass Open Online Courses of Russian Universities,” Vestnik moskovskogo gorodckogo pedagogicheckogo universiteta, no. 4, pp. 50-57, 2018 (in Russian); doi: 10.25688/2072-9014.2018.46.4.05

6. A. Gavrilov and Y. Novitskaya, "Umnaya uchebnaya laboratoriya dlya avtomatizatsii provedeniya laboratornykh rabot” [“Smart School Laboratory for Automation of Laboratory Works”], Computer tools in education, no. 6, pp. 20-32, 2016.

7. M. F. Paulsen, “Experiences with Learning Management Systems in 113 European institutions,” Educ. Technol. Soc., Vol. 6, Iss. 4, pp. 134-148, 2003.

8. V. A. Ryzhov, Y. B. Senichenkov, Y. V. Shornikov, and D. N. Dostovalov, "Kompyuternoe modelirovanie slozhnykh dinamicheskikh sistem. Otsenka potrebnostei v spetsialistakh” [A Program to Determine the Asymptotic Effciency of Convolutional Codes], Computer tools in education, no. 3, pp. 51-60, 2017 (in Russian).

9. L. A. Aleksandrova, E. R. Galimov, and S. S. Pirozhenko, "Problematic aspects of evaluation of competence-oriented training," Scientific notes of the Institute of Social and Humanitarian Knowledge, Vol.1(15), Kazan: UNIVERSUM, pp. 24-29, 2017.

10. L. A. Aleksandrova, E. R. Galimov, and M. S. Tyapkin, “Labor expenses E-learning,” Scientific notes of the Institute of Social and Humanitarian Knowledge, Vol. 1(14), Kazan: UNIVERSUM, pp. 32-37, 2016.

11. Ben Gilad, "Neither a War nor a Game," Competitive Intelligence Magazine, Vol. 9 (6), Nov.-Dec. 2006.

12. L. A. Aleksandrova, E. R. Galimov, Ali Dhahir Mohsin Alramadhan, "Electronic training: problems and solution,” Fundamental and applied scientific research, Ufa, pp. 136-140, April. 2015.

Received 19.02.2019, the final version - 21.03.2019.

Компьютерные инструменты в образовании, 2019

№ 1: 79-87

УдК: 378:147:004

http://ipo.spb.ru/journal

doi:10.32603/2071-2340-2019-1-79-87

\title{
Сервисы цифровой обучающей платформы
}

\author{
Александрова Л. А. ${ }^{1}$, кандидат техн. наук, доцент, ludmilasis@mail.ru \\ Галимов Э. Р. ${ }^{1}$, аспирант, 96bedward@mail.ru \\ ${ }^{1}$ Казанский национальный исследовательский технический университет им. А. Н. Туполева \\ ул. К. Маркса, д. 10, 420111, Казань, Россия
}

\begin{abstract}
Аннотация
В данной работе проанализированы цифровые технологии в современном образовательном процессе, предложены обучающие и контрольные сервисы, сформированные с помощью Learning Management System (LMS), позволяющие организовать активное, творческое и социальное обучение современных специалистов, в соответствии с программой «Цифровая экономика Российской Федерации». В работе анализируются современные технологии обучения, существующие сервисы цифровых платформ. Возможности цифровых платформ продемонстрированы на основе LMS Blackboard. Предложены обучаю-
\end{abstract}


щие и контрольные мероприятия, которые позволяют формировать компетенции специалистов цифровой экономики. Авторами разработаны модели «Деловой игры», реализованные на основе LMS Blackboard и с помощью программного комплекса SMARTlabwork. Представлены результаты анализа параметров качества выполнения различных обучающих и контрольных мероприятий, их параметров, полученные с помощью методов интеллектуального анализа - Data Mining. Рекомендованы существенные признаки контрольных мероприятий и показателей компетентности.

Ключевые слова: система управления обучением, средства обучения и контроля, интеллектуальный анализ данных, электронное обучение.

Цитирование: Александрова Л. А., Галимов Э. Р. Сервисы цифровой обучающей платформы // Компьютерные инструменты в образовании. 2019. № 1. С. 79-87. doi: 10.32603/2071-2340-2019-1-79-87

Поступила в редакцию 19.02.2019, окончательный вариант - 21.03.2019. 